\title{
On line continuous monitoring of subcutaneous tissue glucose in men by combining portable glucosensor with microdialysis
}

\author{
C.Meyerhoff, F. Bischof, F. Sternberg, H.Zier and E. F.Pfeiffer \\ Institut für Diabetes Technologie an der Universität Ulm, Ulm, FRG
}

\begin{abstract}
Summary. For the normalisation of blood glucose levels in diabetic patients by feedback controlled insulin delivery, a self-manageable and reliable method for continuous glucose estimation is still not available. By combining a commercially available needle type dialysis probe (molecular cutoff $20,000 \mathrm{Da}$ ) with a sensitive glucose sensor, we obtained a device for continuous glucose measurement in dialysate. This device was tested in healthy volunteers during a 75 -g oral glucose tolerance test and in Type 2 (non-insulin-dependent) diabetic patients. Venous glucose and subcutaneous sensor signal were followed for $300 \mathrm{~min}$ (ten healthy subjects), $21 \mathrm{~h}$ (three healthy subjects) or $9 \mathrm{~h}$ (seven Type 2 diabetic patients). The recovery of the microdialysis was interindi-
\end{abstract}

vidually different, but after calibration, glucose levels in the dialysate and subcutaneous glucose sensor signal correlated well $(r=0.84-0.95)$. Under the assumption of a physiologic and technical delay between intravenous and subcutaneous glucose, correlation coefficient between intravenous glucose and subcutaneous sensor signal ranged from 0.60 to 0.93 . We conclude that changes in blood glucose could be monitored in the subcutaneous tissue by the microdialysis technique in a continuous on line manner.

Key words: Continuous glucose sensing, enzyme electrode, glucose oxidase, subcutaneous glucose concentration, microdialysis, oral glucose load.
Although automated continuous blood glucose control by an artificial endocrine pancreas was developed several years ago [1,2], a reliable method for continuous selfmonitoring of glucose is still not available. On the other hand, it is not possible for patients to continuously monitor their own blood glucose. It is not advisable for patients to puncture their own veins due to the problems of thrombosis and infection. Hence. if an invasive method is used, the subcutaneous (s.c.) tissue could be the target for glucose estimation. As we reported previously [3], using an enzymatic glucose sensor and the wick technique, the s.c. glucose concentration is equal to the plasma glucose.

There are still considerable problems with implantable needle type enzyme electrodes with a drift of sensor signal and long-term stability [4]. As an alternative, the microdialysis technique might provide dialysates of the extracellular tissue fluid, as shown more than 20 years ago, when amino acids and neurotransmitters were analysed in brain dialysates $[5,6]$. In these studies the dialysates were collected in fractions, and the analytes were measured intermittently [7]. This technique has been used for the estimation of various substrates including glucose in extracellular space of different regions [8, 9].
By combining the outlet of a dialysis probe with a glucose sensor, we obtained a device for continuous measurement of glucose content in tissue dialysate.

The technical description of this device was published previously [10]. The present paper refers to the application of this device in healthy volunteers and diabetic patients. Our study had two aims: the first was to check our continuous glucose sensing system s.c. in vivo in both healthy volunteers and diabetic patients. The second was to examine the microdial sis technique under a standardized glucose challenge (healthy volunteers) or under the conditions of disturbed glucose metabolism (Type 2 diabetic patients).

\section{Subjects, materials and methods}

\section{Healthy volunteers}

Thirteen healthy volunteers (four female, nine male) participated in our study. The age of the subjects was $22.6 \pm 5.0$ years (mean $\pm S D$, range $19-35$ years), the $B M I$ was $22.8 \pm 2.7 \mathrm{~kg} / \mathrm{m}^{2}$ (range 19.2 $29.3 \mathrm{~kg} / \mathrm{m}^{2}$ ). In ten subjects, the duration of the experiment was $300 \mathrm{~min}$. In the remaining three subjects, the experiment was extended to $21 \mathrm{~h}$. 


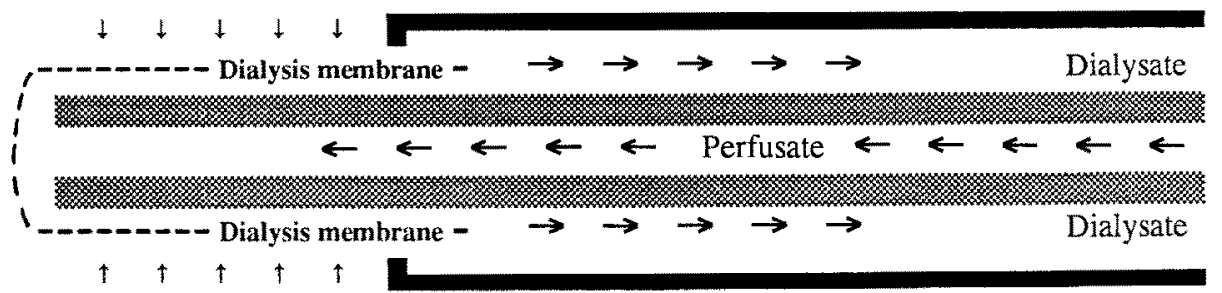

Fig.1. Scheme of the microdialysis technique. The flow of the fluids is indicated by the bold arrows. A steel shaft (black area) is glued to a dialysis membrane (dotted line). In an inner cannula (dotted area) the perfusate (phosphate buffered saline) is transported to the tip of the probe. The probe is placed under the skin, and substances (e.g. glucose) having a concentration gradient compared with the perfusate, diffuse through the dialysis membrane, as indicated by thin arrows

\section{Diabetic patients}

Seven male Type 2 diabetic patients treated by diet, aged $63.7 \pm 5.4$ years (range $56-68$ years) participated in the study. The BMI of the patients was $29.9 \pm 1.7 \mathrm{~kg} / \mathrm{m}^{2}$ (range $27.2-31.2 \mathrm{~kg} / \mathrm{m}^{2}$ ). $\mathrm{HbA}_{1 \mathrm{c}}$ values varied between $5.2 \%$ and $8.5 \%$ (mean $6.3 \% \pm 1.2 \mathrm{SD}$; normal range: $4.6-6.0 \%$ ). The duration of the experiment was $9 \mathrm{~h}$.

All subjects gave their informed consent, and the study was approved by the local ethical committee.

\section{Microdialysis procedure}

A commercially avallable dialysis probe was used with a molecular cutoff of 20,000 Da (CMA/Microdialysis AB, Stockholm, Sweden; polycarbonate/polyether copolymer, outer diameter $500 \mu \mathrm{m}$; membrane length $16 \mathrm{~mm}$ ). It was perfused by means of a roller pump at a flow rate of $4 \mu \mathrm{l} / \mathrm{min}$ (for experiments of $300 \mathrm{~min}$ duration in healthy subjects) or $7 \mu \mathrm{l} / \mathrm{min}$ (for long-term experiments in healthy subjects and experiments in diabetic patients). The perfusion rate was changed, because after $10-12 \mathrm{~h}$ at the lower flow rate, a considerable drift of the glucose sensor signal was seen. Polyvinylchloride pump tubing was obtained from Labokron (Sinsheim, FRG). Phosphate buffered saline $(0.9 \%)$ was used as perfusion fluid. The principle of the microdialysis method is illustrated in Figure 1.

The dialysis probe was inserted under the paraumbilical skin by the following procedure: the surface of the skin was punctured two times (in and out) by a 20 gauge i.v. cannula (Viggo-Spectramed, Helsingborg, Sweden). The steel mandrin was removed, and the dialysis probe was retrogradely inserted into the plastic cannula. The plastic cannula was then removed, thereby drawing the probe under the surface of the skin. No local anaesthesia was used. At the same time, an indwelling catheter was placed in an antecubital vein.

\section{Glucose sensing}

The outlet of the dialysis probe was connected to a flow chamber. A glucose oxidase (GOD) membrane (Ames Division, Miles Lab., Elkhart, Ind., USA) was attached to the flow chamber and covered by a platinum/silver electrode, which was polarized at $700 \mathrm{mV}$. Glucose diffuses through the membrane and is converted by the GOD to gluconolactone and hydrogen peroxide. Hydrogen peroxide is oxidized at the potential of $700 \mathrm{mV}$ leading to a current proportional to the glucose concentration in the flow chamber. The resulting current was amplified, digitalized and the average value of each minute was recorded.

Blood glucose was continuously measured by our Glucosensor Unitec Ulm [11] using a double lumen catheter and additionally every $30 \mathrm{~min}$ by a reference method (23A Glucose Analyzer; Yellow Springs Instruments, Yellow Springs, Ohio, USA).

\section{Calibration}

Before each in vivo experiment, the whole system (microdialysis probe, tubing and flow chamber) was perfused using sterile phosphate buffered saline. The resulting background current of the sensor was recorded and the sensor was calibrated to zero. After a 30 min run-in period following the implantation of the microdialysis probe, blood was drawn and the intravenous (i.v.) glucosensor and s. c. glucosensor were calibrated to the actual blood glucose.

\section{Study protocol}

Healthy volunteers. At time zero, $30 \mathrm{~min}$ after the calibration, the volunteers were given a 75 -g oral glucose load and sensor signals were recorded at $1-\mathrm{min}$ intervals for the following $270 \mathrm{~min}$.

Additionally, the dialysate, when having passed the flow chamber, was collected in 30-min fractions and the glucose concentration was estimated by a colorimetric method (glucose oxidase-peroxidase method [12] with slight variations of the volume in order to adapt to the lower glucose concentrations appearing in the dialysate). In the remaining three subjects, the microdialysis probe was inserted at 16.00 hours the day before the oral glucose load. The perfusion procedure and continuous glucose sensing including calibration was performed in the same way as in the other ten subjects, but was extended to $21 \mathrm{~h}$. The subjects had a normal evening meal and fasted between 22.00 hours and 08.00 hours the following morning. A 75-g oral glucose tolerance test was then performed and s.c. glucose sensor signals were recorded at 1 -min intervals for the following $300 \mathrm{~min}$. Blood was drawn from an indwelling catheter at $2-\mathrm{h}$ intervals during the night and at 30 -min intervals during the glucose tolerance test and subjected to glucose estimation. The same scheme was used in collecting dialysate fractions.

Diabetic patients. At 08.00 hours, the diabetic patients were admitted to the Institute after an overnight fast. The procedure of s.c. and i.v. glucose sensing was performed as in the healthy volunteers. At 09.00 hours and 13.00 hours, the patients were given an $800 \mathrm{kcal}$ meal containing $50 \%$ carbohydrates, $30 \%$ protein and $20 \%$ fat. The values of the $\dot{i} . v$. and s.c. glucose sensors were followed until 18.00 hours.

\section{Statistical analysis}

To estimate the lag-time between changes in $i . v$. and s.c. glucose content, the delay due to the dead-space of the tubing was subtracted and linear regression was applied to i.v. glucose sensor values and s.c. glucose sensor values under the assumption of different lag times. Pearson's correlation coefficient $r$ was used as a measure for the goodness of fit. The assumed lag-time leading to the highest correlation coefficient was considered as a measure of the real delay between changes in i.v. and s. c. glucose sensor signal.

\section{Results}

\section{Healthy volunteers}

Figure 2 shows an example of i.v. and s.c. sensor signal and reference. Intravenous glucose measured by the Glucosensor Unitec Ulm and the reference method were comparable. The correlation coefficient under the assumption of a 6-min delay between i.v. and s.c. glucose sensor signal was 0.85 , as shown in Figure 3 . The results of 


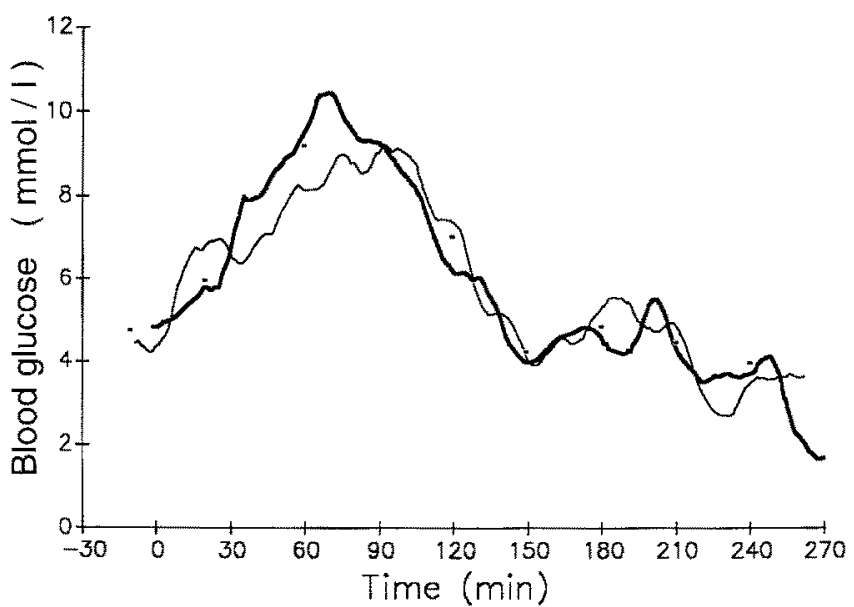

Fig. 2. Measurement of blood glucose (mmol/l; continuously, bold line; reference, $\mathrm{mmol} / \mathrm{l} \mathbf{\mathbf { m }}$ ) and s.c. glucose (calibrated in vivo, thin line) in a healthy volunteer. At time zero a 75 -g oral glucose tolerance test was started

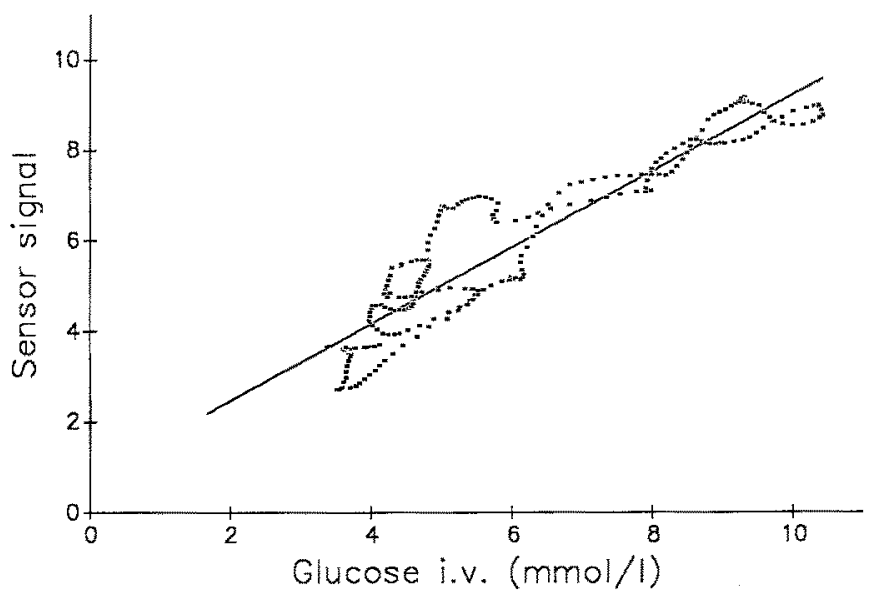

Fig. 3. Correlation between venous blood glucose ( $\mathrm{mmol} / 1)$ and s.c. sensor signal ( $\mathrm{mmol} / 1$, calibrated in vivo) over $270 \mathrm{~min}$ under an assumed 6 -min delay between venous blood glucose and s.c. glucose. The values of the i.v. glucose sensor (horizontal axis) are plotted against the values, which were recorded 6 min later by the s.c. glucose sensor. $r=0.93 ; \mathrm{y}=0.85 \mathrm{x}+13.8 ; n=270$

the linear regression between i.v. and s.c. glucose sensor signals and the corresponding lag-times for each subject are given in Table 1. There was no correlation between BMI and the lag-time between i.v. and s.c. glucose sensor signal. In the subject shown in Figure 4, s. c. glucose sensing was performed for $21 \mathrm{~h}$ after insertion of the microdialysis probe. The glucose tolerance test was performed in the morning of the second day ( 08.00 hours). There is a clear parallel between changes in blood glucose and the s.c. glucose sensor signal. Moreover, dialysate glucose parallels the course of blood glucose as well as the s. c. sensor signal over the whole period.

The subcutaneous glucose sensor signal was closely related to the dialysate glucose concentration estimated by the reference method (Fig. 5). The ratio between dialysate glucose and blood glucose, which we refer to as the recovery of the microdialysis, was individually different, but for each volunteer, correlation coefficients between dialysate glucose and s. c. glucose sensor signal ranged between
0.85 and 0.94 . Figure 6 shows the relationship between blood glucose and dialysate glucose in ten healthy subjects, where the perfusion rate was $4 \mu \mathrm{l} / \mathrm{min}$. As indicated by the standard variation, the recovery of the microdialysis was variable (mean $9.4 \pm 5.36 \%$, range $4.7-14.1 \%$ ) and different between volunteers. The recovery remained constant (average of the recoveries at the 30-min intervals over the period of the glucose load: $9.7 \pm 0.89 \%$ ). There was a negative correlation between $\mathrm{BMI}$ and recovery: recovery $=-1.2 \times \mathrm{BMI}+37, r=-0.5823(n=10$, perfusion rate $4 \mu \mathrm{l} / \mathrm{min})$. This correlation was close to statistical significance $(0.05<p<0.1)$.

\section{Diabetic patients}

The recovery of the microdialysis in the Type 2 diabetic patients varied interindividually between 4.88 and $11.45 \%$ (mean $\pm \mathrm{SD}: 6.70 \pm 2.26 \%$ ), but remained constant over the experimental period. The correlation coefficient between BMI and recovery was $r=-0.43$, which is not statistically significant $(p>0.1)$. An individual example of s.c. glucose sensing in comparison to blood glucose is given in Figure 7; the averaged values of sensor signal $( \pm$ SD) and blood glucose $( \pm S D)$ are shown in Figure 8 . The s.c. glucose sensor signal closely followed the course of blood glucose after the meals.

\section{Discussion}

The fact that the glucose concentration in the dialysate correlated well with the glucose sensor signal demonstrates that, over the period of the glucose tolerance test, only a very slight drift of the glucose sensor signal occurred. This was an improvement when compared with

Table 1. Parameters of linear regression between i.v. and s.c. glucose sensor signals over $270 \mathrm{~min}$ following oral glucose tolerance test and corresponding lag-time

\begin{tabular}{llrlc}
\hline $\begin{array}{l}\text { Subject } \\
\text { no. }\end{array}$ & $\begin{array}{l}\text { Slope } \\
\mathrm{m}\end{array}$ & $\begin{array}{l}\text { Intercept } \\
\mathrm{b}\end{array}$ & $\begin{array}{l}\text { Correlation } \\
\text { coefficient } r\end{array}$ & $\begin{array}{l}\text { Lag time } \\
\text { (min) }\end{array}$ \\
\hline 1 & 1.02 & -2.41 & 0.91 & 15 \\
2 & 0.60 & 0.71 & 0.67 & 0 \\
3 & 0.86 & 1.67 & 0.85 & 13 \\
4 & 0.55 & 3.06 & 0.76 & 0 \\
5 & 0.63 & 2.26 & 0.89 & 3 \\
6 & 0.85 & 0.72 & 0.93 & 6 \\
7 & 0.91 & -2.23 & 0.93 & 5 \\
8 & 0.95 & 0.48 & 0.70 & 0 \\
9 & 1.07 & -0.58 & 0.81 & 4 \\
10 & 0.73 & 3.67 & 0.60 & 0 \\
$11^{\text {a }}$ & 0.67 & -1.43 & 0.58 & 18 \\
$12^{\mathrm{a}}$ & 0.79 & 0.92 & 0.71 & 8 \\
$13^{\mathrm{a}}$ & 1.16 & -1.67 & 0.78 & 8 \\
\hline
\end{tabular}

The relation between i.v. and s. c. glucose sensor is assumed to have the form:

s.c. $(\mathrm{t})=\mathrm{m} \times$ i.v. $(\mathrm{t}-\operatorname{lag}-\mathrm{time})+\mathrm{b}$

where s.c., s.c. glucose sensor signal; i. v., i.v. glucose sensor signal; $t$, time $t ; m$, slope; $b$, intercept

${ }^{a}$ Glucose sensing was performed for $21 \mathrm{~h}$ 


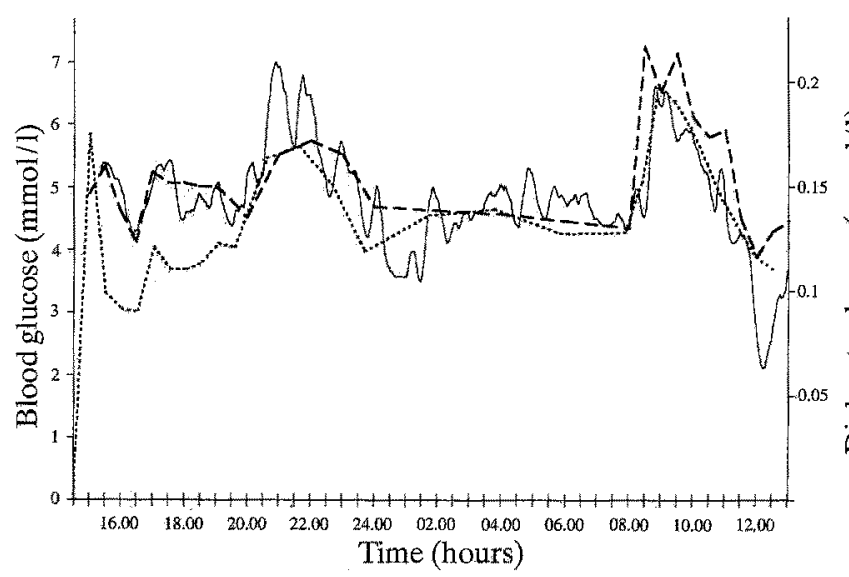

Fig.4. Measurement of blood glucose ( $\mathrm{mmol} / \mathrm{l}$ ) and s.c. glucose (mmoll, calibrated in vivo, thin line) in a healthy volunteer for $21 \mathrm{~h}$ after implantation of the microdialysis probe. At time zero a $75-\mathrm{g}$ oral glucose tolerance test was started
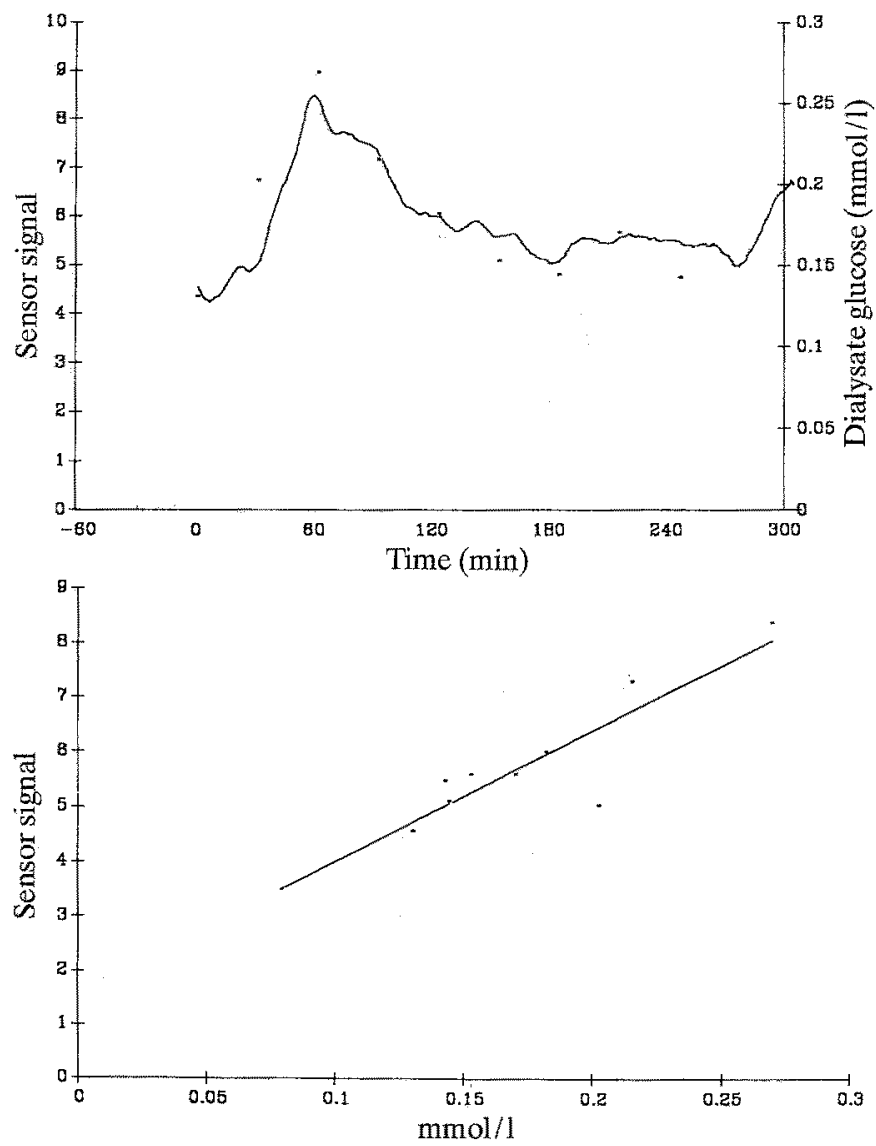

Fig.5. Upper panel: relationship between s.c. dialysate glucose (mmol/l; ) and s.c. sensor signal (mmol/l calibrated in vivo, continuous line). At time zero a $75 \mathrm{~g}$ oral glucose tolerance test was started. Lower panel: correlation between s.c. dialysate glucose content and s.c. glucose sensor signal in the same volunteer, $r=0.87$; $\mathrm{y}=23.9 \times+1.65 ; n=9$

the implantable enzyme electrodes, which showed a considerable drift immediately after implantation $[13,14]$.

The pattern of the s.c. glucose concentrations obtained by the combination of the microdialysis technique and the continuous glucose sensing system closely reflected the profile of blood glucose concentrations in the healthy vol-

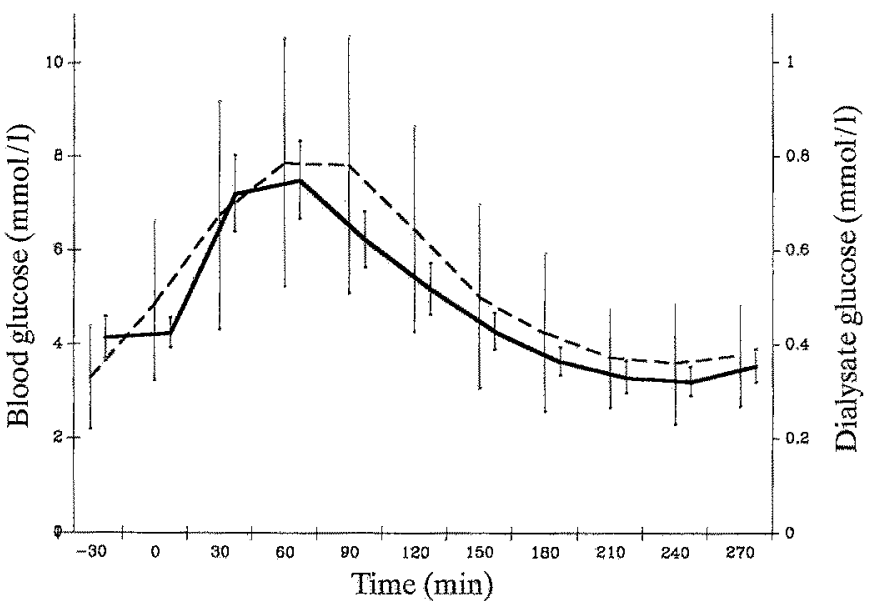

Fig. 6. Relationship between blood glucose (mmol/l, left ordinate; continuous line; $\pm \mathrm{SD}$ - $\mathbf{m}$ ) and s.c. dialysate glucose (mmol/h, right ordinate; broken line, $\pm \mathrm{SD}-\mathrm{O}$ ) in ten healthy volunteers. At time zero a 75 -g oral glucose tolerance test was started

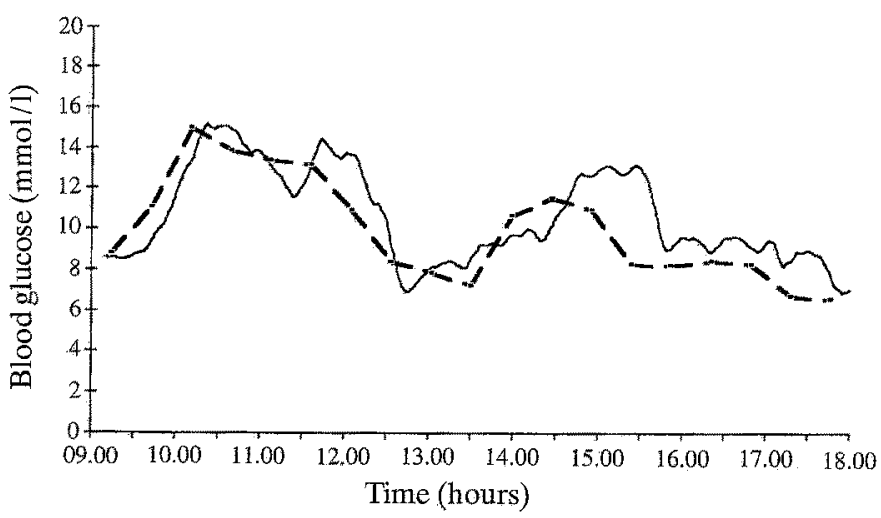

Fig. 7. Measurement of blood glucose (mmol/; broken line) and s.c. glucose ( $\mathrm{mmol} / 1$, calibrated in vivo, thin line) in a Type 2 (non-insulin-dependent) diabetic patient. At 09.00 hours and 13.00 hours a $800 \mathrm{kcal}$ meal was given.

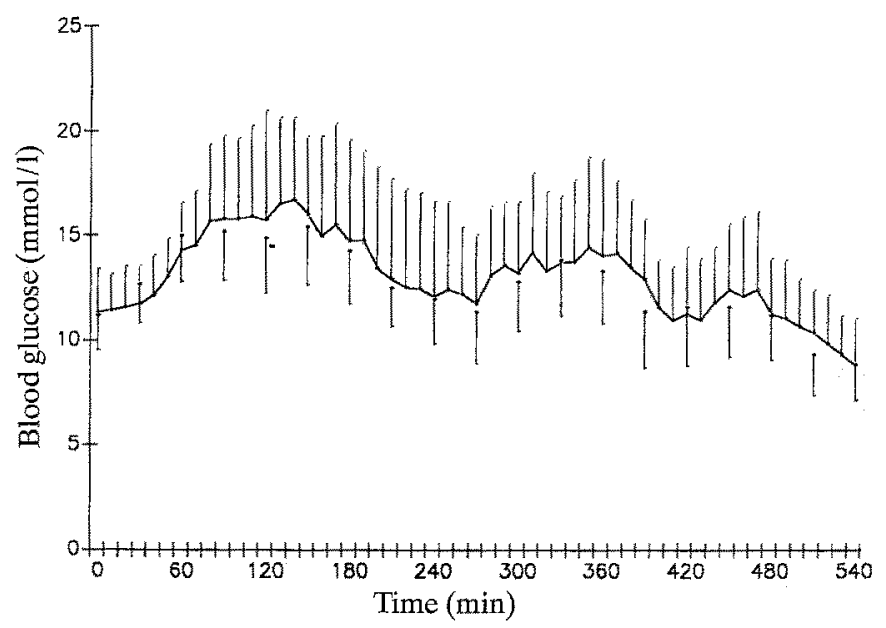

Fig. 8. Blood glucose concentrations at 30-min intervals (mmol/l, closed symbols; - SD) and s.c. glucose concentrations in 10-min intervals (mmol/1, calibrated in vivo, open symbols; $+\mathrm{SD}$ ) in seven Type 2 (non-insulin-dependent) diabetic patients treated by diet. At time $0 \mathrm{~min}$ (09.00 hours) and at time $240 \mathrm{~min}$ (13.00 hours) an $800 \mathrm{kcal}$ meal was given 
unteers as well as in the diabetic patients. A delay of 0-18 min resulted between i.v. and s. c. glucose sensor signal. This value is comparable to most other studies on s.c. glucose measurement using microdialysis $[15,16]$ or enzyme electrodes [17]. The pattern of the s.c. glucose concentrations obtained by our device generally paralleled the course of the blood glucose concentrations up to $21 \mathrm{~h}$, demonstrating both stability of the amperometric glucose sensor and constant permeability of the microdialysis probe.

The relative recovery of the microdialysis (ratio between dialysate glucose and corresponding blood glucose) is known to be dependent upon the perfusion rate [10]. When comparing subjects undergoing microdialysis at the same flow rate, however, the recovery appeared to be interindividually different. After calibration, the s.c. glucose sensor signal and the i. v. glucosensor had a linear relation during the experiment. That also applies in the diabetic patients and in the three subjects when the glucose tolerance test was performed over a considerable length of time $(16 \mathrm{~h})$ after the insertion of the microdialysis probe. This shows that the relative recovery of the microdialysis in each subject did not change substantially during the period of glucose sensing.

In some subjects, the correlation coefficients between s.c. and i.v. glucose sensor signal were comparatively low $(0.58-0.60)$. In view of the fact that at least 270 single values were correlated, this correlation is highly significant.

The interindividual variability of the recovery can be explained several ways: individual tissue reactions which are known to occur after the insertion of microdialysis probes in the brain of rats [18], e.g. oedema, haemorrhage, infiltration, changes in local blood flow, precipitation of fibrin on the dialysis membrane, could influence the permeability of the dialysis membrane and thereby the resistance to glucose diffusion through the membrane. On the other hand, the resistance of the tissue itself to glucose diffusion also needs to be considered. In a mathematical model of microdialysis [19], the latter is the decisive parameter in influencing the recovery of the analyte (in this case: glucose). This resistance of the tissue is dependent, besides analyte-related diffusion characteristics, upon extracellular volume fraction and the metabolism of the analyte. The latter two points may partly contribute to the borderline-statistically significant correlation between BMI and the recovery of the microdialysis in the ten healthy volunteers undergoing microdialysis at a flow rate of $4 \mu \mathrm{l} / \mathrm{min}$. This point needs further investigation in a patient population selected with regard to BMI.

Due to the interindividual changes of the recovery, individual calibration is necessary. We used a one-point calibration in vivo after a zero-point calibration in vitro. This calibration should ideally be done under steady-state conditions. This was the case in our fasted healthy volunteers as well as in the Type 2 diabetic patients, whose fasting blood glucose did not change substantially over the period of calibration. In an animal study [20], a two-point in vivo calibration was performed: one calibration point was the fasting blood glucose, and the second calibration point was the peak after an intraperitoneal glucose load. As this procedure would be difficult to perform under the circum- stances of daily life, for which a device for continuous glucose monitoring in a diabetic patient must function, we used the easier one-point calibration.

Our technique has the advantage of continuously monitoring glucose in the s.c. tissue, compared to previous studies $[16,21]$, where dialysate fractions were collected intermittantly and glucose was estimated by a laboratory method. Since a rupture of the dialysis membrane, due to a sudden movement of the subject cannot be excluded, the technique of Aalders et al. [15], requiring continuous perfusion of the microdialysis tube with GOD, has more risks than ours.

In conclusion, the physiologic changes in blood glucose could be followed in the s.c. tissue by the microdialysis technique in a continuous on line fashion over the range of $3.3-10 \mathrm{mmol} / 1$ (healthy volunteers) or $8.0-16.0 \mathrm{mmol} / \mathrm{l}$, respectively (Type 2 diabetic patients). Further efforts will aim at miniaturization of the system in order to improve the functionality of the sensor.

Acknowledgements. This study was supported by Herbert Weishaupt Dotation, Schwendi (FRG), Landesversicherungsanstalt Württemberg, Stuttgart (FRG), Grant Pf 38/4-2 Deutsche Forschungsgemeinschaft Bonn-Bad Godesberg (FRG) and Landesschwerpunkt "Diabetes mellitus" of the Ministerium für Wissenschaft und Kunst, Baden-Württemberg (FRG).

\section{References}

1. Albisser AM, Leibel BS, Ewart TG, Davidovac Z, Botz CK, Zingg W (1974) An artificial endocrine pancreas. Diabetes 23: 389-396

2. Pfeiffer EF, Thum C, Clemens AH (1974) The artificial beta-cell. A continuous control of blood sugar by external regulation of insulin infusion (glucose-controlled-insulin-infusion-system). Horm Metab Res 6: 339-342

3. Brückel J, Kerner W, Zier H, Steinbach G, Pfeiffer EF (1989) In vivo measurement of sc glucose concentrations with an enzymatic glucose sensor and a wick method. Klin Wochenschr 67: 491-495

4. Kerner W, Pfeiffer EF (1991) The artificial pancreas. In: Samols E (ed) The endocrine pancreas. Raven Press Ltd, New York, pp 441-456

5. Bito L, Davson H, Levin E, Murray M, Snider N (1966) The concentrations of free amino acids and other electrolytes in cerebrospinal fluid, in vivo dialysate of brain and blood plasma in the dog. J Neurochem 13:1057-1067

6. Delgado JMR, DeFeudis FV, Roth RH, Ryugo DK, Mitruka BK (1972) Dialytrode for long term intracerebral perfusion in awake monkeys. Arch Int Pharmacoldyn 198: 9-21

7. Ungerstedt U, Herrera-Marchintz M, Jungnelius U, Ståle L, Tossman U, Zetterstrom T (1982) Dopamine synaptic mechanisms reflected in studies combining behavioural recordings and brain dialysis. In: Kotsiaka $M$ (ed) Advances in dopamine research. Pergamon Press, New York, pp 219-131

8. Benveniste H (1989) Brain microdialysis. J Neurochem 52:16671679

9. Lönnroth P, Smith U (1990) Microdialysis - a novel technique for clinical investigations. J Int Med 227: 295-300

10. Keck FS, Kerner W, Meyerhoff C, Zier H, Pfeiffer EF (1991) Combination of microdialysis and glucosensor permits continuous (on line) s. c. glucose monitoring in a patient operated device: I - in vitro evaluation. Horm Metab Res 23: 617-618

11. Brückel J, Zier H, Kerner W, Pfeiffer EF (1990) Progress in practical endocrinology. The glucosensor unitec Ulm - a portable 
monitor for continuous blood glucose measurement. Horm Metab Res 22: 382-384

12. Raabo E, Terkildsen TC (1960) On the enzymatic determination of blood glucose. Scand J Clin Lab Invest 12: 402-407

13. Pickup JC, Shaw GW, Claremont DJ (1989) In vivo molecular sensing in diabetes mellitus: an implantable glucose sensor with direct electron transfer. Diabetologia 32: 213-217

14. Kerner W, Keck FS, Zier H, Pfeiffer EF (1991) The function of a hydrogen peroxide detecting enzyme electrode is markedly impaired on implantation into human subcutaneous tissue. Diabetes 40 [Suppl 1]: 400A (Abstract)

15. Aalders AL, Schmidt FJ, Schoonen AJM, Broek IR, Maessen AGFM, Doorenbos H (1991) Development of a wearable glucose sensor; studies in healthy volunteers and in diabetic patients. Int J Artif Organs 14: 102-108

16. Jansson PA, Fowelin J, Smith U, Lönuroth P (1988) Characterization by microdialysis of intercellular glucose level in subcutaneous tissue in humans. Am J Physiol 255: E218-220

17. Kerner W, Zier H, Steinbach G et al. (1988) A potentially implantable enzyme electrode for amperometric measurement of glucose. Horm Metab Res 20: [Suppl] 8-13

18. Benveniste H, Diemer NH (1987) Cellular reactions to implantation of a microdialysis tube in the rat hippocampus. Acta Neuropathol (Berl) 74: 234-238
19. Bungay PM, Morrison PF, Dedrick RL (1990) Steady-state theory for quantitative microdialysis of solutes and water in vivo and in vitro. Life Sci 46: 105-119

20. Moatti-Sirat D, Capron F, Reach G et al. (1992) Towards continuous glucose monitoring: in vivo evaluation of a miniaturized glucose sensor implanted for several days in rat subcutaneous tissue. Diabetologia 35: 224-230

21. Bolinder J, Hagström E, Ungerstedt U, Amer P (1989) Microdialysis of subcutaneous adipose tissue in vivo for continuous glucose monitoring in man. Scand J Clin Lab Invest 49: 465 474

Received: 9 April 1992

and in revised form: 20 July 1992

Dr. C. Meyerhoff

Institut für Diabetes Technologie an der Universität Science Park

Helmholtzstrasse 20

W-7900 Ulm

FRG 